\title{
A IMPORTÂNCIA DOS DEVERES FUNDAMENTAIS NA CONSECUÇÃO DA SOCIEDADE ATUAL
}

\author{
Bruno Marcelo Ferreira Fernandes \\ Universidade de Ribeirão Preto - UNAERP, São Paulo \\ Adalberto Simão Filho \\ Universidade de Ribeirão Preto - UNAERP, São Paulo
}

\begin{abstract}
RESUMO: O presente estudo debaterá sobre um instituto que atualmente não tem grande relevo na doutrina e jurisprudência, seja nacional ou estrangeira, mas que mesmo assim não deixa de apresentar elevada importância. Os deveres fundamentais, atrelados aos direitos fundamentais apresentam uma importância ímpar, uma vez que compõem a (sub)constituição do indivíduo. Ademais é classificada como uma categoria jurídico-constitucional autônoma, e que tem se desenvolvido ao longo do tempo de maneira muito semelhante aos direitos fundamentais. Trata-se de um importante debate que influencia a formação da sociedade moderna.
\end{abstract}

PALAVRAS-CHAVE: Direito Constitucional. Deveres fundamentais. Estado. Sociedade.

\section{The importance of fundamental duties in the achievement of today's society}

ABSTRACT: The present study will discuss an institute that currently does not have great importance in the doctrine and jurisprudence, national or foreign, but nonetheless it is not without great importance. Fundamental duties, tied to fundamental rights, are of paramount importance, since they constitute the (sub) constitution of the individual. In addition it is classified as an autonomous legal-constitutional category, and that has developed over time in a very similar way to fundamental rights. It is an important debate that influences the formation of modern society. KEYWORDS: Constitutional right. Fundamental duties. State. Society.

\section{INTRODUÇÃO}

O tema apresentado busca aquecer um debate em torno de um assunto de grande relevância no mundo jurídico, que atualmente é pouco trabalhado pela jurisprudência e doutrina. Tratase do estudo sobre os deveres fundamentais, assunto abordado pela Carta Magna, que possui grande abrangência, e importância na formação do Estado moderno. Não se admite mais a presença de indivíduos detentores de direitos, sem possuírem deveres, seja com a Pátria, com o Poder Público ou com a sociedade. A evolução da sociedade, reclamam a presença de indivíduos mais solidários e comprometidos com os deveres fundamentais.

Nesse artigo será apresentado a definição do que vem a ser os direitos fundamentais, sua origem por volta do século XVIII, e formação, que é dividida em dimensões, até suas primeiras impressões na Constituição brasileira. Será traçado um paralelo entre direitos humanos e direitos fundamentais. Por conseguinte, se definirá o que vem a ser "dever", em sentido lato, suas nuances aplicadas ao direito, e as diferenças entre direitos e deveres.

Há uma simbiose essencial entre os deveres constitucionais e os direitos constitucionais, sendo os dois institutos de grande relevância para que haja a vida em sociedade. Assim é necessário que se estude os dois institutos de forma equilibrada confrontando as duas realidades, para 
se afastar abusos que possam ocorrer por parte dos Estados, mas também retirar cidadãos da inércia, de que é somente o Estado, que proporciona a consecução da sociedade. Reconhece-se assim que não há somente deveres do Estado para com o cidadão, mas que o contrário também é verdadeiro.

É preciso descortinar o ambiente dos deveres, fazer uma teorização ao se respeito e delimitar o assunto para uma melhor formação da sociedade.

\section{DIREITOS FUNDAMENTAIS}

Direitos fundamentais são definidos como os direitos individuais básicos de todo cidadão. Compreendem garantias asseguradas na seara individual e coletiva (direito a vida, igualdade de todos os cidadãos perante a lei), direitos sociais (educação, lazer e trabalho), e direitos políticos.

O termo direitos fundamentais teve suas primeiras impressões no movimento políticocultural, ocorrido na França, que culminou na Declaração dos Direitos do Homem e do Cidadão, em 1789. ${ }^{1}$ Essa declaração foi um documento elaborado, pautado na liberdade, igualdade e fraternidade universal, acima de qualquer interesse particular. Nessa época a França findava a era de um regime absolutista, que outorgava capacidade suprema a um monarca. As ideias ventiladas pelo iluminismo e pelo humanismo mudaram a ótica do Estado, que passou a servir aos interesses dos cidadãos e a garantir direitos e deveres.

A expressão "direitos humanos" e "direitos fundamentais" são tratados por muitos autores como sinônimos. Esse trabalho se filia a linha traçada pelos estudos de Péres Luño ${ }^{2}$, que as diferencia, uma vez que o termo direitos humanos é semanticamente muito abrangente de significados, de maneira que, por vezes é correlacionado a direitos do homem ou direitos naturais.

Marcelo Neves define os direitos humanos, como uma aspiração normativa universal de qualquer pessoa, com abrangência em âmbito internacional e de maneira abstrata. ${ }^{3}$ Cita-se como exemplo os Tratados e as Convenções Internacionais assinadas por países e que vinculam a ambos.

Já os direitos fundamentais se hospedam na seara do direito interno de cada Estado, resultado de um processo de constitucionalização dos direitos humanos. ${ }^{4}$ Sua formação está em constante alteração, de acordo com as mudanças da sociedade. São fundamentais para o homem, pois tratam todos de maneira igual. São formalmente reconhecidos, tem aplicação concreta e material, sua limitação é oriunda da soberania popular.

Luigi Ferrajoli define os direitos fundamentais como normas tético-deônticas, ou seja, hipotéticas e moralmente obrigatórias sendo tais direitos, por conseguinte, indisponíveis e inalienáveis. ${ }^{5}$

A partir da Segunda Guerra Mundial foi que se iniciou o processo do novo constitucionalismo, que inseriu nas Constituições valores e princípios vinculativos. Vale lembrar que esse período em que se aderiu a Constituição formal envolveu basicamente a estruturação, a formação

1 PÉRES LUÑO, Antonio Enrique, Derechos humanos, Estado de Derecho y Constitución, p. 30. QUADROS DE MAGALHÃES, José Luiz. Direito Constitucional, t. p.42.

2 Idem, p. 30.

3 NEVES Marcelo. A força simbólica dos direitos humanos, p. 144. Revista Brasileira de Direito Público, a. 1, n. 3, out./dez. 2003.

4 GALUPPO, Marcelo Campos. O que são direitos fundamentais? p. 33 In: SAMPAIO, Jose Adercio Leite (Coord.). Jurisdição Constitucional e direitos fundamentais. Belo Horizonte: Mandamentos, 2002.

5 FERRAJOLI, Luigi. Por uma teoria dos direitos e dos bens fundamentais, 2011, p. 88. 
do Estado e a inserção de garantias e direitos fundamentais. Inicia-se então a "era das Constituições formalizadas (formais) em um documento escrito". ${ }^{6}$ Todo o processo de formação dos direitos fundamentais demandou muitas lutas e sacrifícios, para se chegar ao modelo atualmente utilizado.

De maneira didática, a doutrina os classifica em gerações ou dimensões. Vale salientar que os direitos fundamentais se complementam de forma que as gerações de direitos são concorrentes entre si. Não há sobreposição de dimensões ou gerações.

A primeira geração dos direitos fundamentais engloba o direito à vida e a liberdade. Direitos que determinam limites e garantem a esfera privada de cada indivíduo. Esses direitos individuais foram desenvolvidos no século XVIII. Garantias formais de liberdade, igualdade e propriedade, conferindo a todos os indivíduos os mesmos direitos subjetivos. Trata-se de direitos de atuação negativa do Estado $^{7}$, ou seja, período do Estado Liberal.

Com o fim da primeira Guerra Mundial, já no século XX, o mundo vivia um cenário de profunda desolação. Período de maior exploração da história do homem, em que homens, mulheres e crianças trabalhavam até 17 horas por dia sem nenhum tipo de direitos garantidos e com remuneração ínfima. A população trabalhadora se encontrava em completo estado de miséria. Essa situação vivida no Estado Liberal, em que não havia qualquer participação do Estado na formação da sociedade eclodiu numa crise da sociedade liberal, marcada por um capitalismo monopolista voltado a produção industrial desenfreada e sem regras.

Assim, surge a segunda geração de direitos, que compreende os direitos sociais, culturais e econômicos, caracterizados pela busca da satisfação de prestações sociais e do movimento com ideias antiliberais. Essa geração passou a garantir o direito ao trabalho, educação, saúde e lazer.

A terceira geração diz respeito ao direito de paz, de autodeterminação dos povos, do sadio meio ambiente, da boa qualidade de vida, da conservação do patrimônio histórico e cultural, também chamados de direitos da fraternidade ou de solidariedade. Para a doutrina clássica há somente essas três gerações de direito. Ocorre que há alguns autores como Paulo Bonavides que defendem mais 2 gerações, definidas como quarta geração e a quinta geração de direito.

A quarta geração se resume a globalização dos direitos fundamentais e a sua institucionalização. Enquadram-se à democracia, o direito à informação e o pluralismo político. ${ }^{8}$ A quinta geração por conseguinte, compreende o direito à paz como direito constitucional.

No Brasil, a primeira vez que se falou de direitos fundamentais foi com a Constituição Federal de 1946 na perspectiva de se restaurar a democracia, após o longo período ditatorial com Getúlio Vargas. As primeiras impressões dos direitos fundamentais previram garantias de primeira geração, concernentes à liberdade, à vida e à propriedade. A grande relevância dos direitos fundamentais ocorreu com a promulgação da Constituição de 1988, denominada "Constituição Cidadã", em que passou a dar destaque a diversos direitos tanto na seara individual quanto na coletiva.

A Carta Magna de 1988 em seu primeiro artigo prevê: "A República Federativa do Brasil formada pela união indissolúvel dos Estados e Municípios e do Distrito Federal, constitui-se em Estado Democrático de Direito [...]". A definição de Estado democrático de direito apareceu a primeira vez com a promulgação da Carta Magna de 1988. Essa previsão se distancia e muito do estado liberal de direito, pois este garante tanto a esfera individual, quanto a social de direitos.

6 FERNANDES, Bernardo Gonçalves. Curso de Direito Constitucional. $7^{\mathrm{a}}$ ed., São Paulo, Editora Juspodium. p. 34.

7 BONAVIDES, Paulo. Curso de direito constitucional, 14. ed., São Paulo, Malheiros, 2004. p. 563-564.

8 BONAVIDES, Paulo. Curso de Direito Constitucional. 13 ${ }^{\text {a }}$ ed. São Paulo: Malheiros, 2003. p. 523. 
Na definição dada por Gregório Assagra Almeida o Estado democrático de direitos é o "Estado da justiça material, da transformação da realidade social, da tutela jurídica ampla, dinâmica, aberta, concretizante a direitos individuais e coletivos." 9

Ademais, a Constituição de 1988 conferiu, conforme art. 60 § 4 IV, status de cláusula pétrea aos direitos fundamentais, afastando dessa maneira a possibilidade de abolí-los ou de afastá-los. Sua aplicação é garantida, por força dos $\S \S 1^{\circ}$ e $2^{\circ}$, do art. $5^{\circ}$, da CR/88, de maneira imediata.

\section{DEVERES FUNDAMENTAIS}

\subsection{Definição do quem vem a ser o "dever"}

Há na literatura jurídica uma ampla gama de livros e artigos que discorrem acerca dos direitos fundamentais constitucionais, no entanto, pouca produção voltada a explanar sobre os deveres fundamentais. Esse desequilíbrio no tratamento de tais assuntos é decorrente de erros passados, seja por parte de indivíduos ou por parte do Estado, que agiram com desrespeito aos cidadãos em relação aos seus direitos. Uma série de atitudes desumanas levou muitas Constituições a preverem em seu bojo direitos e garantias constitucionais.

Essa bandeira levantada por jurisconsultos de garantia a direitos humanos, por um lado conferiram garantias aos cidadãos, mas que em contrapartida impulsionou a um círculo vicioso de marasmo por parte da sociedade, que agora passaram a enxergar no Estado seu viés paternalista e assistencialista.

O conceito de direitos individuais começou a ser aventado somente a partir do século XVIII com as revoluções que ocorreram, como forma de afastar os abusos exercidos pelo Estado. Nos primórdios, a definição dos direitos e deveres fundamentais eram extraídas a partir dos conceitos da moral cristã e religiosa.

Inicia-se com uma definição mais aprofundada do que vem a ser o termo "dever". De acordo com os estudos de Fernando Bastos de Ávila, "dever" indica uma necessidade, fundada num determinismo físico, ou seja, um fenômeno que não pode deixar de ocorrer. Como exemplo, cita-se o eclipse solar que ocorrerá em uma data e momento determinado. "Dever", como substantivo, assume um sentido abstrato e um sentido concreto.

Na definição do filósofo alemão Emmanuel Kant significa estar "obrigado a", "ligado a", "preso a". Fernando de Bastos apresenta o seguinte questionamento: "como é possível que o homem seja obrigado a, necessitado a, a fazer, a agir de tal modo, se ele é um ser livre? "Em resposta a essa indagação: Se tratasse de uma necessidade inelutável, com a força de um determinismo físico, não existiria liberdade e não existiria nenhum merecimento em cumprir o dever". Nessa situação o dever não seria cumprido pelo indivíduo, mas arrastado por ele. Há uma ambiguidade contida no significado da palavra dever e a liberdade do homem não é absoluta.

A liberdade é limitada fisicamente a aquilo que está acima da minha força. Eu não posso transportar aquela montanha; eu não posso descobrir os mistérios do câncer. Nada disso, porém suprime a minha liberdade; basta, aliás, que eu não queira transportar aquela montanha, para não

9 ALMEIDA, Gregório Assagra de. Direito material coletivo: superação da summa divisio direito público e direito privado por uma nova summa diviso constitucionalizada, 2008, p. 352. 
sentir esta limitação da minha liberdade. Mas esta não é limitada apenas fisicamente. Experimentamos, também, limitações de outra natureza, como quando diante de uma criança inocente, eu sei que não posso estrangulá-la. Essa limitação da liberdade é precisamente a obrigação moral, a única que pode ligar a necessidade de um ser livre, sem suprimir a liberdade. Ávila indaga de onde o "eu devo" tira sua força imperativa? ${ }^{10}$

A filosofia já se debruçou arduamente na busca dessa resposta. A ideia menos criticada e mais aceita é a da existência de um Deus, Criador e Salvador, capaz de impor leis ao homens livres, que não são arbitrárias, mas decorrentes de uma natureza livre, consciente e social. Só a justiça do criador incorruptível, dá uma definitiva eficácia a essas leis, e ao imperativo moral.

Em sentido concreto o "dever" está ligado a uma obrigação específica, ou seja, a uma tarefa determinada, imposta por uma autoridade competente. Alguns desses deveres são tidos por comuns a todos os indivíduos. Mais concretamente temos na doutrina cristã os dez mandamentos, que são deveres impostos a todos os homens sem distinção. Além desses deveres concretos essenciais, há outro denominado de deveres concretos ligados à condição ou função que desempenham na comunidade. Esses são os deveres de um pai de um lado e do outro o dever dos filhos; ou de um lado são os deveres do Estado e de outro os deveres dos subordinados. ${ }^{11}$

Plácido e Silva conceitua “dever", como substantivo, a obrigação imputada a uma pessoa de fazer ou deixar de fazer algo, conforme o direito e a moral. Nesse viés, assume dupla acepção o termo dever, que é dever moral e dever jurídico. O dever moral é assumido pelo agente de forma livre e voluntária, pois não se trata de uma ordem legal expressa, que o obrigue a cumprir. Em contrapartida, o dever jurídico tanto poderá ser oriundo de uma obrigação, a partir de um contrato em que obriga os contratantes, quanto do respeito a princípios elementares do direito como da equidade e da ordem jurídica, de maneira que o indivíduo não incorra em ofender direito alheio.

\subsection{A gênese dos deveres}

Para uma maior compreensão, é salutar nos debruçarmos sobre as teorias dos deveres, trazida por alguns autores, a fim de tecer considerações a partir de estudos realizados ao longo da história.

\subsubsection{Cícero}

Partindo dos escritos de Cícero, cuja obra é intitulada Dos Deveres, o autor romano apresenta os deveres como a face imprescindível das virtudes e dela decorrenciais. Nesse viés, na virtude dos indivíduos há uma série de deveres, que precisam ser cumpridos. $\mathrm{O}$ autor define como fonte dos deveres o decoro, que por sua vez, é derivado de quatro outras fontes como a: a justiça, a generosidade, a prudência e a moderação. Os deveres têm grande ligação com a justiça e essa acarreta grandes responsabilidades. "O primeiro dever imposto à justiça é não fazer mal a

\footnotetext{
10 ÁVILA, Fernando Bastos de. Pequena Enciclopédia de Moral e Civismo. Rio de Janeiro: Companhia Nacional de Material de Ensino, Ministério da Educação e Cultura-MEC, 1967, p. 158, verbete - dever.

11 ÁVILA, Fernando Bastos de. Pequena Enciclopédia de Moral e Civismo. Rio de Janeiro: Companhia Nacional de Material de Ensino, Ministério da Educação e Cultura-MEC, 1967. p. 159.
} 
ninguém, a menos que se tenha de rebater um insulto; o segundo é empregar em comum os bens de comunhão e tratar como próprios apenas os que nos pertencem." 12

A justiça tem como base e alicerce a boa-fé e a sinceridade.

A obra dos Deveres, apresenta um alto teor moral, pois define que os deveres somente poderão deixar de ser cumpridos quando se estiver diante de um outro dever de maior relevância. $\mathrm{Na}$ seara da atividade política, sustenta-se que as grandes ações civis sempre se sobrepõem às ações militares. Ele sustentava ainda que o abandono da coisa pública é sinal de extrema injustiça.

No que diz respeito a mutabilidade dos deveres, há uma relação diretamente proporcional de atuação no tempo, de maneira que com o avanço da idade dos indivíduos, esses se sujeitam a deveres diferentes àquelas pessoas mais jovens. Nessa ideia, um idoso tem deveres distintos aos impostos a pessoas mais novas. ${ }^{13}$

\subsubsection{Emmanuel Kant}

Emmanuel Kant, filósofo germânico, em suas obras Fundamentos da Metafísica dos Costumes de 1785 e a Metafísica dos Costumes de 1797, definem o dever como imperativo categórico e hipotético. Antonio Xavier Teles, de maneira mais sucinta, interpretou e expôs o pensamento de Kant, do que vem a ser o imperativo categórico e hipotético. No primeiro caso, o indivíduo age segundo seus próprios princípios internos, de forma autônoma. Seria o caso em que alguém encontra uma carteira contendo um valor considerável e, que através dos dados pessoais, identifica o dono e os devolve. Essa atitude é totalmente calcada na honestidade, sem nenhuma intervenção externa para impulsioná-lo a agir daquela forma.

No segundo caso, o imperativo hipotético, a obrigação moral está atrelada a uma condicionante, que se resume em "se... então". No caso do exemplo citado acima, O indivíduo devolve a carteira com o dinheiro, não por motivos internos, mas com medo de que alguém descubra a sua atitude de se apoderar de algo que não lhe pertence. ${ }^{14}$

Kant define que o dever deriva da razão, e será bom, quando esse se basear a partir do imperativo categórico. A razão é que dá luz a vontade. A vontade por sua vez se traduz na faculdade de se escolher nada mais do que a razão, mesmo diante de inclinações que afastem o bom pensamento do indivíduo. Assim, a ideia de dever para Kant está ligada a boa vontade do indivíduo, independentemente de inclinação pessoal. Como exemplo desse dever cita-se o mandamento bíblico de amar o próximo, mesmo que este seja seu inimigo. Nesse exemplo, a inclinação é de que não se volte com amor para com o inimigo, mas a vontade se traduz em fazer o bem por dever. Trata-se de um amor prático e não patológico.

Na obra Metafísica dos costumes, Kant distingue o "dever" da "virtude" e diferencia o "dever" de "direito". A partir do seu pensamento, o dever de virtude compreende uma modalidade de deveres éticos intrínsecos a vontade do indivíduo. Os deveres de direito, por sua vez, impõem uma estrita obrigação, que é previamente delimitada e definida aos indivíduos.

${ }^{12}$ CÍCERO, Marco Túlio. Dos Deveres. Título original: De Officiis. Tradução: Alex Marins. São Paulo: Editora Martin Claret, 2002, p. 37 (Livro I, VII).

${ }^{13}$ CÍCERO, Marco Túlio. Dos Deveres. Título original: De Officiis. Tradução: Alex Marins. São Paulo: Editora Martin Claret, 2002, p. 69 (Livro I, XXXIV)

${ }^{14}$ Apud TELES, Antônio Xavier. Educação Moral e Cívica - introdução à cidadania. $8^{a}$ ed. São Paulo: Companhia Editora Nacional, [1982], p. 159. 


\title{
2.2.3. Gregório Robles
}

Gregorio Robles apresenta uma crítica ao pensamento contemporâneo de se fundamentar os direitos humanos, totalmente descolados dos deveres e valores morais. Para o autor, este pensamento surgiu a partir do movimento contratualista, que pregava a supremacia dos direitos sobre os deveres. Historicamente, com maior veemência no mundo ocidental, surgiu a teoria dos direitos humanos, que não apresenta nenhuma vinculação aos deveres e valores morais. De acordo com os ensinamentos de Robles, esse descolamento gera uma desmoralização da vida pública e privada, e consequentemente, a falta de deveres da sociedade desencadeia em uma multiplicação de direitos, sem controle e sem responsabilidade de seus indivíduos.

O estado de natureza foi um tempo em que os homens tinham plenos direitos e liberdades. O grande problema é que não havia nenhum tipo de garantias, de maneira a não haver leis e nem deveres, que garantissem que a posse atual de direitos e bens que perdurassem no futuro a favor de seu proprietário. Nesse período a plena liberdade é ilusória, pois desencadeia um alto grau de desconfiança, insegurança, desorganização e luta de poder por parte dos indivíduos.

Robles atribui aos contratualistas Thomas Hobbes e a John Locke a superação do movimento da escola escolástica, que compreende a ética da política a partir da Teologia. Nessa seara, os direitos estavam diretamente subordinados a ideia do dever. A existência de Deus era que dava origem aos fenômenos sociais, políticos e jurídicos. Não se falava em direitos perante Deus, somente em deveres. Os direitos permeavam somente a esfera entre os homens e não destes para com Deus.

Francisco Gerson Marques de Lima ${ }^{15}$ ensina que:

\begin{abstract}
A filosofia política individualista tomou por partida o homem abstrato, desvinculado de todo vínculo social e, portanto, de todo dever. Os homens coexistiam naturalmente uns com os outros, numa relação de conflituosidade intensa. No estado de natureza, por não haver leis nem deveres, todos têm direito a tudo, sem necessidade de obrigação alguma e com ampla liberdade.
\end{abstract}

Os homens, em busca de maior segurança, na realização do pacto social, abrem mão de um estado máximo de direitos, vivido no estado de natureza, para um estado mínimo de direitos agora no pacto social. Hobbes analisa o conflito do homem no estado de natureza, que agora busca uma maior segurança da vida e de seus bens, formando assim seus valores éticos e morais. Essa pensamento individual, de acordo com a definição dada por Gregorio Robles é chamada de construção política e moral "justificação do estado burguês mais descarado e descarnado". ${ }^{16}$

Dentro da ideia trazida por Hobbes e Locke é possível inferir que no estado de natureza há a plenitude de direitos, e a ausência de deveres. A construção do que vem a ser os deveres surgem somente na sociedade organizada, após a constituição do pacto social. Dessa maneira, os deveres são construídos artificialmente a partir de um acordo dos homens, situação totalmente díspares aos direitos que já existem e possuem uma identidade própria desde os primórdios da natureza humana.

\footnotetext{
${ }^{15}$ LIMA, Francisco Gerson Marques de. Dos deveres constitucionais: o cidadão responsável in: http://servicos.prt7.mpt.gov.br/artigos/2011/Deveres\%20Constitucionais.pdf . pesquisado em: 20/03/2017.

${ }^{16}$ ROBLES, Gregorio. Los derechos fundamentales y la Ética em la Sociedad Actual. p. 46 (trecho de tradução nossa)
} 


\subsubsection{Hans Kelsen}

De acordo com Hans Kelsen, com sua visão positivista, é a norma de conduta que alvitra uma obrigação ao sujeito. A norma propriamente dita não é o dever, mas sim o conteúdo da norma que a prescreve. Assim, a primeira é expressão normativa da segunda, em âmbito jurídico. De acordo com o pensamento de Kelsen, não há qualquer inferência moral ao dever.

$\mathrm{O}$ autor ainda apresenta uma distinção entre o dever e a responsabilidade. O dever recai sobre o indivíduo a que está previsto na norma. Já a responsabilidade tem a possibilidade de recair sobre terceiros. Assim, a norma exige determinada conduta do sujeito e também uma sanção que poderá recair em terceiros. Como exemplo cita-se a responsabilidade patrimonial na ação de execução, em que pode recair para outras pessoas a dívida do devedor. ${ }^{17}$

Na visão do autor o direito precede ao dever, ante a prevalência daquele. No campo da Moral há a inversão da prioridade.

\subsection{Dos deveres fundamentais na perspectiva constitucional}

A partir da conceituação dada pelos doutrinadores do que vem a ser o dever, passa-se agora a enfrentar o cerne proposto por esse trabalho, que é os deveres fundamentais constitucionais.

Indubitavelmente, eles adentram a natureza dos deveres jurídicos, e por isso recebem uma abordagem pelo direito. Apresentam um alto grau de generalização no trato dado pela Constituição, e sua definição está fortemente ligada ao caráter político e ao modelo de Estado em que ordenamento está inserido.

De maneira mais clara, pode-se apontar para uma definição entre dever e obrigação. $O$ primeiro, pode-se dizer que apresenta uma maior abrangência, já vez que se trata de um termo utilizado por várias áreas do conhecimento como pela filosofia, direito, religião, moral, política, etc. A obrigação por sua vez, é termo mais restrito, empregado no meio jurídico. Tem em sua definição elementos e consequências bem definidas.

Claudino Piletti salienta que a cada direito há um dever intrinsecamente ligado. Nessa seara, o direito de manifestação do pensamento está apenso ao dever de deixar que outros possam se manifestar livremente. $\mathrm{O}$ autor ainda aponta haver alguns deveres fundamentais dos brasileiros frente ao Estado que são: a) o de votar; b) de pagar impostos; c) de prestar o serviço militar. ${ }^{18}$

De acordo com a biblioteca integrada LISA, os poderes do Estado estão limitados a dois quesitos: 1) de maneira particular pelo direito público, pois os poderes do Estado são voltados a consecução dos objetivos sociais; 2) em sentido amplo, pelo direito natural.

Essa visão conceitual trazida por Piletti de que a definição de um está diretamente ligada ao outro, cria um ciclo vicioso e que prejudica a compreensão e delimitação do sistema de deveres fundamentais.

Nessa linha, os deveres fundamentais pertencem a ceara dos direitos fundamentais e assim, o primeiro não é apenas prestações ou abstenções que devam partir somente por parte do

${ }^{17}$ KELSEN, Hans. Teoria Pura do Direito. João Baptista Machado. Título Original: Reine Rechtslehnre. São Paulo: Martins Fontes, 2000, p. 128 e ss.

18 PILETTI, Claudino. OSPB - Organização Social e Política Brasileira. 30ª ed. São Paulo: Atlas, 1993, p. 79. 
Estado. Trata-se de uma via de mão dupla em que o cidadão tem responsabilidade e deveres na construção da cidadania e da sociedade.

Dalmo Dallari ${ }^{19}$ ensina que:

[...] é importante assinalar que os direitos da sociedade são, ao mesmo tempo, deveres. Pode parecer estranho dizer que uma pessoa tem o dever de exercer os seus direitos, porque isso dá a impressão de que tais direitos são convertidos em obrigações. Mas a natureza associativa da pessoa humana, a solidariedade característica da humanidade, a fraqueza dos indivíduos isolados quando devem enfrentar o Estado ou grupos sociais poderosos são fatores que tornam necessária a participação de todos nas atividades sociais. Acrescente-se a isso a impossibilidade de viver democraticamente se os membros da sociedade não externarem suas opiniões e vontade. Tudo isso torna imprescindível que os cidadãos exerçam seus direitos de cidadania.

Os deveres fundamentais, tanto no Brasil quanto na Europa, não apresentam o mesmo tratamento dedicado aos direitos fundamentais, que segundo Alcântara ${ }^{20}$ se justiça por dois motivos que são: a) a relutância do cidadão, de modo geral, em reconhecer deveres; b) a imposição de defesa da relação hipossuficiente do cidadão frente ao Estado.

Os deveres fundamentais se resumem a deveres do Estado para com a comunidade e sendo assim, somente Eles podem determinar e configurar a disciplina legal pertinente ao tema para a sua realização. ${ }^{21}$

Conforme explicação de Menezes, é possível se distinguir 3 grupos de relações intersubjetivas de titulares ativos:

Em primeiro lugar, os chamados deveres fundamentais clássicos (dever de defesa da pátria, dever de pagar impostos, deveres políticos), por constituírem pressupostos necessários ao funcionamento do Estado, têm neste o seu titular ativo. Depois, há os deveres fundamentais de conteúdo econômico, social ou cultural (deveres de trabalhar, de cultivar a terra, de comunidade. "São deveres cujo cumprimento tem sobretudo a ver com a defender e promover a saúde, de defender o ambiente, de defender e valorizar o patrimônio cultural, etc.). Estes tem como titular a existência do próprio estado". Por derradeiro, deveres há cujos ativos são determinados grupos de pessoas enquanto titulares de direitos fundamentais, como é caso do dever dos pais de manutenção e educação dos filhos. ${ }^{22}$

Há situações em que o Estado se vê no polo passivo da relação dos deveres constitucionais, "quer na organização e funcionamento de serviços administrativos especializados, que englobam o dever do contribuinte de pagar impostos; quer na realização de tarefas estaduais e de imposição de obrigações constitucionais, estas ligadas a deveres econômicos, sociais e culturais.

${ }^{19}$ DALLARI, Dalmo. Direitos e deveres da cidadania. Disponível em www.dhnet.org.br/sos/textos/deveres.htm. Acesso em 16/03/2017.

20 ALCANTARA, Michelle Alencar da Cruz. A face oculta dos direitos humanos: os deveres fundamentais. Disponível em: http://www.conpedi.org/manaus/arquivo/AnaisMichele\%20Alencar\%20da\%20daCruz\%20Alcantara.pdf. Acesso em: 16/03/2017.

${ }^{21}$ NABAIS, Jose Casalta. O dever fundamental de pagar impostos: contributo para a compreensão constitucional do estado fiscal contemporâneo. Coimbra: Almedina, 2004.

22 MENEZES, Jose Lima de. Deveres fundamentais na Constituição do Brasil: o tributo. Recife, UFPE, 2003. 187p. Dissertação (Mestrado em Direito). Universidade Federal de Pernambuco, 2003. 


\subsection{A relação entre os deveres fundamentais e os direitos fundamentais}

Conforme abordado no presente trabalho, é nítido perceber a assinalagmaticidade que há entre os direitos e os deveres fundamentais, embora se admita que os deveres fundamentais integrem os direitos fundamentais, de maneira a defini-los como a (sub)constituição do indivíduo.

Nesse interregno, a relação entre direitos e deveres fundamentais, a partir dos estudos do professor lusitano Nabais apontam que a) os deveres fundamentais precisam ser interpretados e ambientado nos termos e critérios conforme os direitos fundamentais; b) os deveres fundamentais estão submetidos aos ao regime geral dos direitos fundamentais; c) a delimitação do cerne dos direitos pelos deveres fundamentais e vice versa, formam um suporte para o legislador limitar ou condicionar liberdades e garantias constitucionais; d) os deveres ligados a direitos sociais, econômicos e culturais, são também definidos como direitos-deveres ou direitos funcionalizados, chamados de direitos de solidariedade..$^{23}$

\subsection{Deveres fundamentais quanto ao seu conteúdo e regime de aplicabilidade}

Os deveres fundamentais se subdividem em 1) deveres positivos ou negativos - são aqueles ligados a um comportamento comissivo de seus destinatários, como o dever de prestar serviço popular ou de pagar tributos; 2) deveres aplicáveis mediatamente ou imediatamente - são os casos em que há previsão expressa do dever na Constituição da República, e tem a aplicação imediatamente aplicável. Como exemplo cita-se a prestação obrigatória do serviço militar. Já, no caso de mediatamente aplicável é quando o dever necessita da complementação do legislador ordinário; 3) deveres autônomos (estrito senso) e não autônomos - o que os diferencia é a relação com os direitos fundamentais, quanto à autonomia. Os deveres fundamentais não autônomos (direitos-deveres ou deveres-direitos) são os que apresentam conteúdo coincidente, ao menos em parte, com direitos fundamentais aos quais se encontram associados. Já os deveres fundamentais autônomos (estrito senso) são aqueles com conteúdo próprio, que não se vinculam com o apresentado por direitos fundamentais ${ }^{24}$; 4 ) deveres de conteúdo cívico-político - versam sobre a sociedade em si, ou seja, sobre o compromisso dos indivíduos com o exercício e a permanência do próprio Estado.

No trato dado aos deveres tem que se tomar cuidado de não despender um olhar unilateral, em que se foca ou somente o Estado ou o cidadão. O estudo dos direitos fundamentais teve origem na primeira dimensão de direitos, chamados também de liberdades públicas, e que previa deveres apenas ao Estado. Na contramão se tem governos despóticos, autoritários, em que é o Estado o detentor de direitos incontáveis e os cidadãos obrigado a seguir inúmeros deveres.

Como já dito não se sustenta trabalhar na linha de que os deveres são o contrário dos direitos, de maneira a concluir que esse pensamento gera um ciclo vicioso. A análise a partir de doutrinas que abordam os Direitos Humanos, se apegam a um protecionismo dos cidadãos e por

${ }^{23}$ MENEZES, Jose Lima de. Deveres fundamentais na Constituição do Brasil: o tributo. Recife, UFPE, 2003. p. 120124.

${ }^{24}$ GRADVOHL, Michel Andre Bezerra Lima. Deveres fundamentais: Conceito, Estrutura e Regime. Disponível em: http://docplayer.com.br/22743212-Deveres-fundamentais-conceito-estrutura-e-regime.html . Acessado em 17/03/ 2017. 
consequência, a uma passividade desses, frente a um Estado paternalista e responsável por políticas de desenvolvimento.

Faz-se necessário partir do princípio do que vem a ser o Estado, que é um ente criado a partir de um suposto contrato social, em que os homens abram mão de suas liberdades, como forma de se unirem e formarem o Estado. Esse novo ente, só atuará a partir da participação mútua de todos os indivíduos daquela comunidade. Trata-se de um dever dos cidadãos e que a sociedade é a responsáveis pelo desenvolvimento, tutela e manutenção do Estado.

Já é hora de se implantar uma ótica mais atuante dos direitos humanos, em que se insira os deveres correlatos aos direitos.

O português Nabais defende a tese de que é preciso colocar os deveres no mesmo patamar constitucional dos direitos. Para o lusitano, o processo da formação dos deveres se assemelha em muito às gerações dos direitos, que historicamente tem-se transformado e ganhado camadas.

No entendimento do referido autor, não há criação de direitos, esses são reconhecidos pelo constituinte, através de mudanças sociais que os reconhece, diferentemente do que acontece com os deveres, que são instituídos pelo constituinte. Dessa maneira, a Constituição é o único meio legítimo autorizado a criar e determinar deveres fundamentais. ${ }^{25}$

Nabais admite que há deveres impostos pelo legislador ordinário, denominados de deveres legais, que não estão previstos na Constituição. Esses para serem exigidos necessitam ser motivados pelo legislador. Assim, somente admite-se os deveres fundamentais que estão previstos na Constituição.

O autor lusitano apresenta um paralelo entre os co-irmãos direitos fundamentais e deveres fundamentais:

\begin{abstract}
Os deveres fundamentais se configuram como posições jurídicas passivas (não ativas), autônomas (face aos direitos fundamentais), subjetivas (já que exprimem uma categorias subjetiva e não uma categoria objetiva), individuais (pois tem por destinatários os indivíduos, e só por analogia as pessoas coletivas) e universais e permanentes (pois tem por base a regra da universalidade ou da não discriminação).
\end{abstract}

A partir destas notas, torna-se relativamente fácil distinguir os deveres fundamentais de certas figuras próximas que, não raro, aparecem deveres fundamentais: a) dos deveres constitucionais orgânicos ou organizatórios (que não passam de competências constitucionais de exercício vinculado quanto ao na); b) dos limites (máxime restrições) legislativas aos direitos fundamentas que, ao amputarem o conteúdo ou parte do conteúdo constitucional não essencial de cada direito, nos fornecem o conteúdo constitucional dos direitos fundamentais que vale na prática; c) dos deveres correlativos dos direitos fundamentais (ou deveres de direitos fundamentais tout court), que não são mais do que a face passiva dos direitos; d) das garantias institucionais (como imprensa livre, a sobretudo figuras jurídicas de natureza objetiva; e) das tarefas constitucionais estrito senso, que tem por destinatário exclusivamente o estado e visam vincular os seus órgãos à produção de certos resultados em matéria de organização econômica ou social, política ou administrativa. $^{26}$

${ }^{25} \mathrm{Na}$ doutrina há um entendimento inverso ao do lusitano Nabais, que amparado no art. 5, CF prevê: que os direitos fundamentais não se reduzem à prescrição constitucional, eis que podem ser criados e elastecidos por outras normas, inclusive internacional.

${ }^{26}$ NABAIS, Jose Cassalta. A face oculta dos direitos fundamentais: os deveres e os custos dos direitos. Disponível em (www.agu.gov.br/ce/cenovo/revista/05042002JoseCasaltaAfaceocultadireitos_01.pdf), acessado em 21/03/2017. 
Importante pontuar que é possível traçar uma linha de definição do que vem a ser o conteúdo dos deveres fundamentais, já que posicionam e determinam o lugar dos indivíduos na sociedade.

Quanto ao regime dos deveres fundamentais, Nabais apresenta a aplicação de alguns princípios como da i) universalidade; ii) da igualdade, enquanto proibição do arbítrio; iii) da não discriminação em razão de critérios subjetivos ou de critérios interditos pela carta magna; iv) da proporcionalidade, conforme os critérios da necessidade, adequação e proporcionalidade em sentido estrito; v) tutela judicial.

Os deveres fundamentais, diferente do que ocorre com os direitos fundamentais, em regra não são aplicáveis imediatamente, dependem de uma concretização constitucional. O legislador ordinário não tem nenhum tipo de obrigatoriedade de legislar sobre os deveres. Ele está habilitado e não obrigado a complementar o texto constitucional no que tange aos deveres fundamentais. Assim, há de certa forma, liberdade por parte do legislador para definir e atribuir qualquer tipo de sanção pelo não cumprimento de um dever por parte do cidadão.

Para Ricardo Lobo Torres os deveres fundamentais são correspectivos aos direitos fundamentais uma vez que de um lado exige uma conduta, por outro garante o exercício da liberdade. Nesse viés, os deveres estão contidos na parte constitutiva da Constituição. Não se confunde um instituto com o outro, a menos que esteja diante de um Estado Totalitário. ${ }^{27}$

\subsection{A importância ativa dos deveres}

Há diversos deveres que se relacionam com os direitos, dentre os quais coletivos, individuais, metaindividuais, que coabitam para a garantia da dignidade dos cidadãos. Nessa linha, tem-se o direito de exercer qualquer atividade e o direito de trabalhar; o dever por parte do Estado de garantir educação e o direito de estudar; o dever de respeitar o próximo e o direito de ser respeitado; deveres que as instituições estão submetidas de se sujeitar às ordens impostas pelo judiciário.

Há ainda outros deveres previstos como o dever de prestar socorro, como forma de solidariedade para com o próximo; dever de comunicar surtos de doenças às autoridades, de maneira a contribuir com o poder público; o dever da não intervenção nos negócios internos e externos do Estado, de maneira a prejudicar a vida política e a soberania.

Os deveres de submissão dos encarcerados a seguir normas e regras no período em que ficar recolhido sob a égide do Estado, como de comportamento, obediência as regras, trabalho higiene, etc.

Os deveres podem ser considerados e chamados de custo para se viver em sociedade. Olivier Wendell Holmes pronunciou a seguinte frase: "os impostos são o que pagamos por uma sociedade civilizada. ${ }^{28}$ Os impostos, definidos como um dever fundamental, é o preço que se paga para se viver em uma sociedade organizada. Isso se traduz em de um lado liberdade aos cidadãos e de outro solidariedade para manutenção da mesma.

\footnotetext{
27 TORRES, Ricardo Lobo. A cidadania multidimensional na era dos direitos, Teoria dos Direitos Fundamentais. Rio de Janeiro: Renovar, 1999. p. 313.

${ }^{28}$ Charles Adams, For Good and Evil. The Impact of Taxes on the Course of Civilization, 2 ed., Madison Books, Lanham. New York. Oxford, 1999. p. 64.
} 


\section{CONSIDERAÇÕES FINAIS}

Trata-se de um tema pouco explorado na doutrina e jurisprudência, e que também carece de simpatia: os deveres. As dificuldades a respeito do referido tema têm origem histórica na relação do Estado com seus indivíduos, em que, inicialmente, tem se o primeiro como o detentor soberano de direitos e o segundo como cumpridor de deveres, de maneira a legitimar inúmeras atrocidades como as grandes guerras e abusos do Estado para com seus súditos.

Os direitos humanos surgiram para garantir e equilibrar a relação entre os sujeitos e o Estado, como forma de trazer um maior equilíbrio entre eles. Esse movimento passou a garantir direitos e garantias fundamentais do cidadão frente ao Estado.

O estudo dos deveres desperta o senso de responsabilidade do cidadão em tomar uma postura mais ativa, frente ao Estado, e mais responsável na sociedade em que vive. Tal expectativa arremata os espaços deixados pelas teorias de direitos fundamentais. A lógica dos deveres é aumentar a sinergia entre os membros da sociedade para disseminação da participação dos indivíduos na sociedade.

Os deveres fundamentais ou também denominados custos lato senso dos direitos, se definem pela responsabilidade comunitária assumida pelas pessoas para viverem em comunidade. Para alguns autores fala-se em uma nova forma de estado solidário, que se preocupa e ter como marca a solidariedade dos homens com a sociedade presente e futura que virão.

O Estado de Direito é eivado de diversos custos financeiros públicos para se manter. Não se admite falar em direitos fundamentais separados de seus deveres respectivos. Somente se terá um Estado eivado da plenitude de liberdades, a partir do devido reconhecimento dos deveres constitucionais por parte dos cidadãos.

\section{REFERÊNCIAS}

ALCANTARA, Michelle Alencar da Cruz. A face oculta dos direitos humanos: os deveres fundamentais. In: Anais do XIV Congresso Nacional do CONPEDI/AM. CONPEDI: Manaus, nov. 2007. p. 446-463. Disponível em: http://www.conpedi.org/manaus/arquivo/AnaisMichele\%20Alencar\%20da\%20daCruz\%20Alcantara.pdf. Acesso em: 16 mar. 2017.

ALMEIDA, Gregório Assagra de. Direito material coletivo: superação da summa divisio direito público e direito privado por uma nova summa diviso constitucionalizada, Belo Horizonte: Editora Del Rey, 2008.

ÁVILA, Fernando Bastos de. Pequena Enciclopédia de Moral e Civismo. Rio de Janeiro: Companhia Nacional de Material de Ensino, Ministério da Educação e Cultura-MEC, 1967.

BONAVIDES, Paulo. Curso de direito constitucional, 14. ed. , São Paulo, Malheiros, 2004.

CÍCERO, Marco Túlio. Dos Deveres. Título original: De Officiis. Tradução: Alex Marins. São Paulo: Editora Martin Claret, 2002.

DALLARI, Dalmo de Abreu. Direitos e deveres da cidadania. São Paulo: Moderna, 1998. Disponível em www.dhnet.org.br/sos/textos/deveres.htm. Acesso em 16 mar. 2017.

FERNANDES, Bernardo Gonçalves. Curso de Direito Constitucional. $7^{\mathrm{a}}$ ed., São Paulo, Editora Juspodium. 
FERRAJOLI, Luigi. Por uma teoria dos direitos e dos bens fundamentais. Tradução de. Alexandre Salim et al. Porto Alegre: Livraria do Advogado, 2011.

GALUPPO, Marcelo Campos. O que são direitos fundamentais?. p. 33 In: SAMPAIO, Jose Adercio Leite (Coord.). Jurisdição Constitucional e direitos fundamentais. Belo Horizonte: Mandamentos, 2002.

GRADVOHL, Michel Andre Bezerra Lima. Deveres fundamentais: Conceito, Estrutura e Regime. Disponível em: http://docplayer.com.br/22743212-Deveres-fundamentais-conceito-estrutura-e-regime.html . Acesso em 17 mar. 2017.

KELSEN, Hans. Teoria Pura do Direito. João Baptista Machado. Título Original: Reine Rechtslehnre. São Paulo: Martins Fontes, 2000.

LIMA, Francisco Gerson Marques de. Dos deveres constitucionais: o cidadão responsável. Disponível em: http://www.lexml.gov.br/urn/urn:lex:br:rede.virtual.bibliotecas:capitulo.livro:2006;1000767813. Consultado em: 20/02/2017.

MENEZES, Jose Lima de. Deveres fundamentais na Constituição do Brasil: o tributo. Recife, UFPE, 2003. 187p. Dissertação (Mestrado em Direito). Universidade Federal de Pernambuco, 2003. Disponível em: <https://repositorio.ufpe.br/bitstream/handle/123456789/4419/arquivo5577_1.pdf?sequence=1\&isAllowed=y> Acesso em 18 nov. 2017.

NABAIS, Jose Casalta. O dever fundamental de pagar impostos: contributo para a compreensão constitucional do estado fiscal contemporâneo. Coimbra: Almedina, 2004.

NABAIS, Jose Casalta. A face oculta dos direitos fundamentais: os deveres e os custos dos direitos. Disponível em: (www.agu.gov.br/ce/cenovo/revista/05042002JoseCasaltaAfaceocultadireitos_01.pdf), acessado em 21/03/2017.

NEVES, Marcelo. A força simbólica dos direitos humanos. Revista Eletrônica de Direito do Estado, Salvador, n.4, novembro/dezembro de 2005. Disponível em: <https://www.researchgate.net/publication/43921452_A_forca_simbolica_dos_direitos_humanos> Acesso em: 15 nov. 2017. Revista Brasileira de Direito Público, a. 1, n. 3, out./dez. 2003.

NUNES, Pedro. Dicionário de Tecnologia Jurídica. 12a ed. 2a tir. RJ, Freitas Bastos, 1993, verbete - "dever".

PÉRES LUÑO, Antonio Enrique. Derechos humanos, Estado de Derecho y Constitución, Inprenta: Madri, Tecnos, 1986. p. 30. p. 30.

PILETTI, Claudino. OSPB - Organização Social e Política Brasileira. 30ª ed. São Paulo: Atlas, 1993.

ROBLES, Gregorio. Los derechos fundamentales y la Ética em la Sociedad Actual. Madri: Civitas, 1992.

TORRES, Ricardo Lobo. A cidadania multidimensional na era dos direitos, Teoria dos Direitos Fundamentais. Rio de Janeiro: Renovar, 1999.

Recebido em: 1 maio 2018. Aceito em: 5 abr. 2019. 